\title{
Colonial nesting of Asian openbill storks (Anastomus oscitans) in Nandankanan Wildlife Sanctuary, Odisha
}

\begin{abstract}
A field study on nesting habits of Asian openbill stork (Anastomus oscitans) was conducted during breeding seasons of 2015 and 2018 at Nandankanan Wildlife Sanctuary, Odisha, India. Observations revealed the stocks arrived for nesting in July and most of them leave the place by December. Nest characteristic and nesting habits including nest size, nest height, nest depth, nesting tree species, nesting material collection, number of chicks, weaning of chick etc. of Asian openbill storks are reported.
\end{abstract}

\author{
Volume 4 Issue I - 2019 \\ RK Mohapatra,' BP Panda, ${ }^{2}$ MK Panda,' S \\ Purohit, ${ }^{3}$ SP Parida, ${ }^{4}$ KL Purohit, ' JK Das,' \\ HS Upadhyay' \\ 'Nandankanan Biological Park, Bhubaneswar -754005, Odisha, \\ India \\ 'ITER, Siksha 'O' Anusandhan Deemed University, Bhubaneswar \\ -751030, Odisha, India \\ ${ }^{3}$ DBCNR, Central University of Orissa, Koraput-764021, \\ Odisha, India \\ ${ }^{4}$ Dept. of Zoology, Centurion University, Bhubaneswar- 752050, \\ Odisha, India
}

Correspondence: Rajesh Kumar Mohapatra, Nandankanan Biological Park, Odisha, India, Pin-754 005, Tel +9199 3756 3742, Email rajesh.wildlife@gmail.com

Received: January 10, 2019 | Published: February 08, 2019

\section{Introduction}

Asian openbill storks Anastomus oscitans (AOS) are the smallest among the nine stork species found in India. ${ }^{1,2}$ They are pale grey storks with black scapulars and reimages, black tail, short reddish legs and a swollen looking bill with a narrow gap between mandibles. ${ }^{1}$ Adult birds have a prominent gap between down-curved upper and recurved lower mandible as an adaptation for grasping snails which is their main prey. However young birds are born without gap in the bill. ${ }^{3}$ They are widely distributed in the plains and the peninsula of the Indian subcontinent. ${ }^{1,4}$ Although mostly resident within their ranges, these birds cover long distances in response to weather suitability and food availability for overwintering and breeding. They breed during the monsoon between July and September. ${ }^{5}$ Previous observations have also reported their congregation in nesting colonies with the onset of south-west monsoon from mid June to January. ${ }^{6-8}$ Colonial nesting site of AOS at Nandankanan Wildlife Sanctuary (NWS) is considered as second largest heronry of the state of Odisha, Eastern India with nesting report since 1999. But, information and published literatures on the nesting habits, population trend and habitat preference of AOS at NWS are inadequate and inconsistent. The present communication intended to report the details of colonial nesting habits of these storks at NWS.

\section{Materials and method}

The study was carried out between June, 2015 and December, 2018 at Nandankanan Wildlife Sanctuary $\left(20^{\circ} 23^{\prime} 08^{\prime \prime}\right.$ to $20^{\circ} 24^{\prime} 10^{\prime \prime} \mathrm{N}$ and $85^{\circ} 48^{\prime} 09^{\prime \prime}$ to $85^{\circ} 48^{\prime} 13^{\prime \prime} \mathrm{E}$ ) in the state of Odisha, Eastern India (Figure 1). The sanctuary spreads over an area of $4.37 \mathrm{sq} . \mathrm{km}$. and has wetland areas more than $1.01 \mathrm{sq} . \mathrm{km}$, which provides a suitable feeding and breeding habitat for many migratory and resident birds including AOS. The sanctuary enjoys a moderately hot humid climate around $30^{\circ} \mathrm{C}$ with annual average rainfall of $1350 \mathrm{~mm}$. The vegetation is of moist mixed deciduous type. ${ }^{9}$ The natural forest areas of Nandankanan is home to a rich assemblage of free-living wild animals including 13 species of mammals, 15 species of reptiles, 123 species of birds, 20 species of amphibians, 85 species of butterflies and 51 species of spiders. ${ }^{10-13}$ The documented bird species of the sanctuary includes two species of storks, namely painted stork and Asian openbill stork.
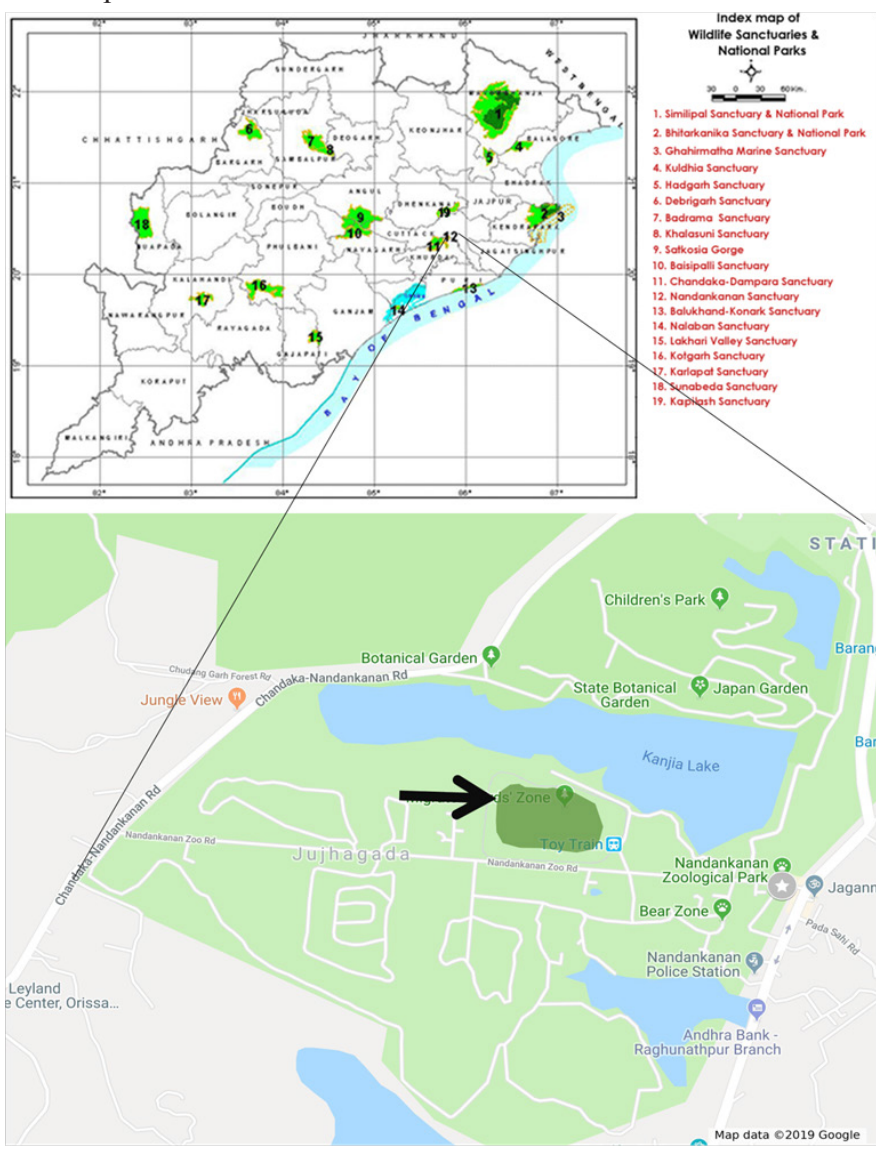

Figure I AOS nesting site in Nandankanan Wildlife Sanctuary, Odisha, India. 
Field observations on nesting colonies carried out ad libitum from June to December every year. Colony is defined as a group of storks nesting on a contiguous canopy that may have more than one tree. Observations were made with naked eye or with 10x binoculars during day time only. A detailed census of nesting colonies was carried out during first week of October every year. Nesting trees were identified following Panda and Panda. ${ }^{9}$ Occupied nests were determined by presence of adult storks and/or their egg or chicks. Information like number of nests on each tree, species of nesting tree and number of storks present on the nests was collected during first week of October every year with minimal disturbances to the nesting storks. To gather information regarding nest characteristic including size, depth and height from the ground, we measured 50 apparently intact abandoned nests (after fledglings are fledged out of the nests) during $3^{\text {rd }}$ week of December, 2018.

\section{Observations}

The species usually form monospecific colonies with an affinity to nest on the upper and upper middle canopy. The colonial nesting was recorded in 20 species of trees with maximum number of nests on Pterospermum heyneanum tree (Table 1). Other important nesting tree species are Ficus benghalensis, Streblus asper, Aegle marmelos, Syzygium cumini, Putranjiva roxburghii, Strychnos nux-vomica, Melia azadirach, Cassia siamia etc. Nests are constructed at $4.57 \mathrm{~m}-10.67 \mathrm{~m}$ height from ground. The diameter of the nests varies from $30-61 \mathrm{~cm}$ and with $20-36 \mathrm{~cm}$ high nesting materials. The nests are shallow and have a depth of $3.5 \mathrm{~cm}-6 \mathrm{~cm}$. The birds start arriving in the month of July and begin to occupy the earlier vacated nests, if available, or make new nests. Around third week of July, most of the trees in the nesting areas are occupied and the storks arriving late had no option other than to choose a preoccupied nesting trees for nesting, which often resulted in intraspecific fights. Collection of nesting material continues from July till November. The nesting material includes twigs, leaves and grasses. The number of chicks in the AOS nests varies from 1-3 (Figure 2). We observed chick in some AOS nests around mid August, and the young storks feeding on snail (weaning) was sighted in first week of October (Figure 2). During this four-year study period, we observed increasing trend in the number of occupied nests (Figure 3). AOS nests were recorded in $212.75 \pm 16.32$ trees on which $2117.75 \pm 415.89$ nests and $8477.5 \pm 1658.76$ number of storks was observed during study period (Table 1). The highest number of trees with nests were of P. heyneanum (33.01\%) followed by S. nuxvomica $(12.81 \%)$, A. indica $(8.58 \%)$ and G. maulata $(8.11 \%)$ (Figure 4). The highest number of nests were recorded in $P$. heyneanum (38\%), followed by S. nux-vomica (14\%), F. benghalensis (11\%) and A. indica (7\%) (Figure 5). Nesting of AOS occurred $73 \mathrm{~m}$ to $89 \mathrm{~m}$ away from roads. Most of the storks leave the nesting site by December except few who stay as resident birds.

Table I Year wise nesting details of openbill storks at Nandankanan Wildlife Sanctuary, Odisha, India

\begin{tabular}{|c|c|c|c|c|c|c|c|c|c|c|c|c|c|}
\hline \multirow{2}{*}{ SI. No. } & \multirow{2}{*}{$\begin{array}{l}\text { Name of the tree used } \\
\text { for nesting }\end{array}$} & \multicolumn{4}{|c|}{ No. of trees } & \multicolumn{4}{|c|}{ No. of nests } & \multicolumn{4}{|c|}{ No. of Open bill storks } \\
\hline & & 2015 & 2016 & 2017 & 2018 & 2015 & 2016 & 2017 & 2018 & 2015 & 2016 & 2017 & 2018 \\
\hline I & Pterospermum heyneanum & 55 & 54 & 69 & 103 & 525 & 510 & 817 & 1403 & 2124 & 2040 & 3268 & 5612 \\
\hline 2 & Strychnos nux-vomica & 18 & 25 & 31 & 35 & 258 & 305 & 282 & 396 & 1028 & 1220 & 1128 & 1584 \\
\hline 3 & Azadirachta indica & 25 & 17 & 11 & 20 & 195 & 102 & 116 & 223 & 362 & 408 & 464 & 892 \\
\hline 4 & Ehretia laevis & 8 & 8 & 7 & 10 & 43 & 45 & 39 & 108 & 319 & 180 & 156 & 432 \\
\hline 5 & Streblus asper & 15 & 18 & 6 & 10 & 79 & 89 & 36 & 73 & 219 & 356 & 144 & 292 \\
\hline 6 & Putranjiva roxburghii & 0 & 0 & 5 & 9 & 0 & 0 & 31 & 191 & 0 & 0 & 144 & 764 \\
\hline 7 & Diospyros melanoxylon & 0 & 0 & 0 & 9 & 0 & 0 & 0 & 108 & 0 & 0 & 0 & 432 \\
\hline 8 & Pongamia pinnata & 0 & 0 & 3 & 8 & 0 & 0 & 58 & 101 & 0 & 0 & 232 & 404 \\
\hline 9 & Terminalia arjuna & 0 & 0 & 3 & 2 & 0 & 0 & 85 & 36 & 0 & 0 & 340 & 144 \\
\hline 10 & Ficus benghalensis & 15 & 17 & 7 & I & 357 & 412 & 69 & 68 & 782 & 1648 & 276 & 272 \\
\hline II & Adina cordifolia & 7 & 8 & 7 & I & 50 & 55 & 51 & 17 & 205 & 220 & 204 & 68 \\
\hline 12 & Aegle marmelos & 7 & 6 & 2 & 1 & 37 & 30 & 15 & 10 & 170 & 120 & 60 & 40 \\
\hline 13 & Melia azedarach & 0 & 0 & 0 & I & 0 & 0 & 0 & 7 & 0 & 0 & 0 & 28 \\
\hline 14 & Gliricidia maculate & 25 & 29 & 15 & 0 & 80 & 92 & 59 & 0 & 315 & 368 & 236 & 0 \\
\hline 15 & Stereospermum colais & 0 & 0 & 11 & 0 & 0 & 0 & 158 & 0 & 0 & 0 & 632 & 0 \\
\hline 16 & Alangium lamarckii & 8 & 9 & 4 & 0 & 54 & 69 & 51 & 0 & 1430 & 276 & 204 & 0 \\
\hline 17 & Mimusops elengi & 0 & 0 & 5 & 0 & 0 & 0 & 35 & 0 & 0 & 0 & 140 & 0 \\
\hline 18 & Cassia siamia & 15 & 17 & 5 & 0 & 75 & 78 & 20 & 0 & 297 & 312 & 80 & 0 \\
\hline 19 & Syzygium cumini & 15 & 12 & 0 & 0 & 90 & 80 & 0 & 0 & 145 & 320 & 0 & 0 \\
\hline \multirow[t]{2}{*}{20} & Diospyros ovalifolia & 9 & 8 & 0 & 0 & 42 & 51 & 0 & 0 & 170 & 204 & 0 & 0 \\
\hline & Total & 222 & 228 & 191 & 210 & 1885 & 1918 & 1927 & $274 I$ & 7566 & 7672 & 7708 & 10964 \\
\hline
\end{tabular}




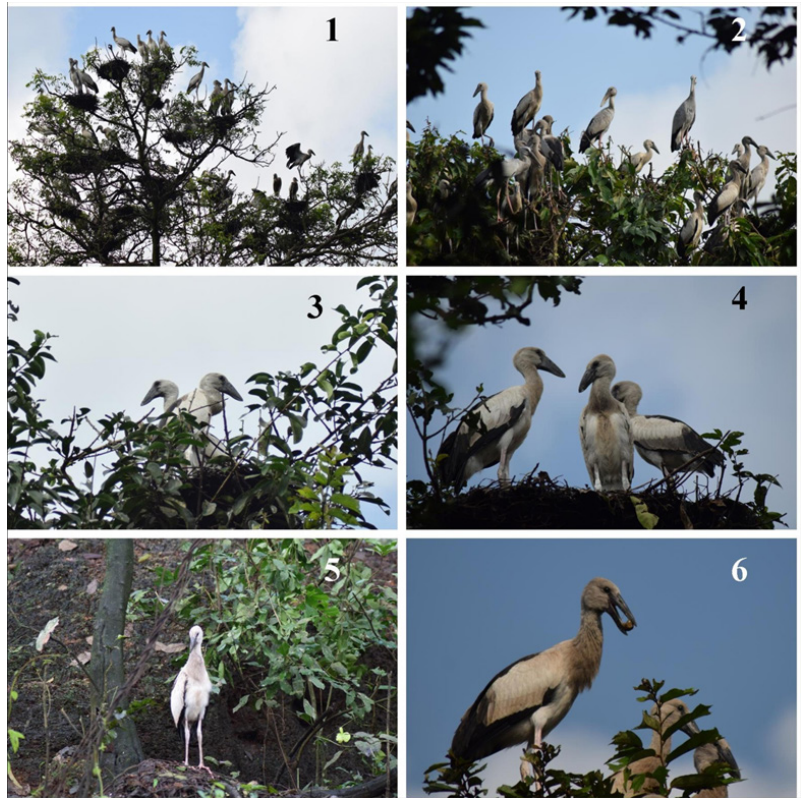

Figure 2 Nesting of openbill stork at Nandankanan Wildlife Sanctuary, India. I) Colonial nests of AOS, 2) roosting openbill storks, 3) nest with two surviving hatchlings, 4) nest with 3 surviving hatchlings. 5) AOS fledgling fallen on ground, 6) fledgling feeding on feeding on snail.

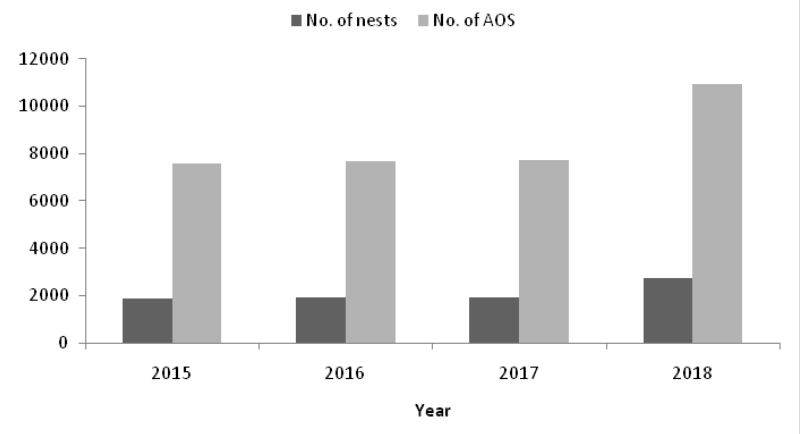

Figure 3 Number of nest and number of AOS during study period (2015-18).

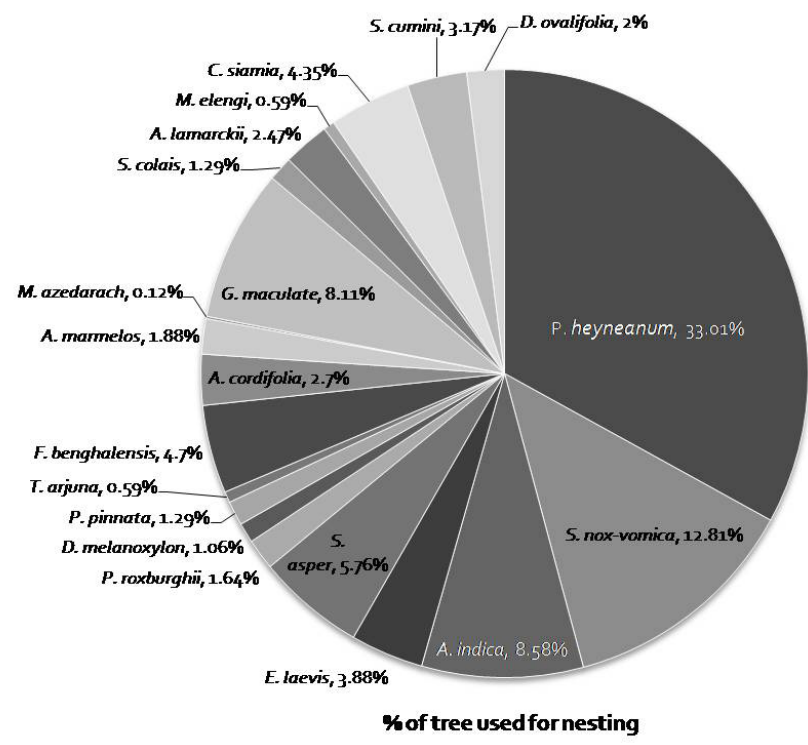

Figure 4 Trees used for nesting by AOS and its species composition.

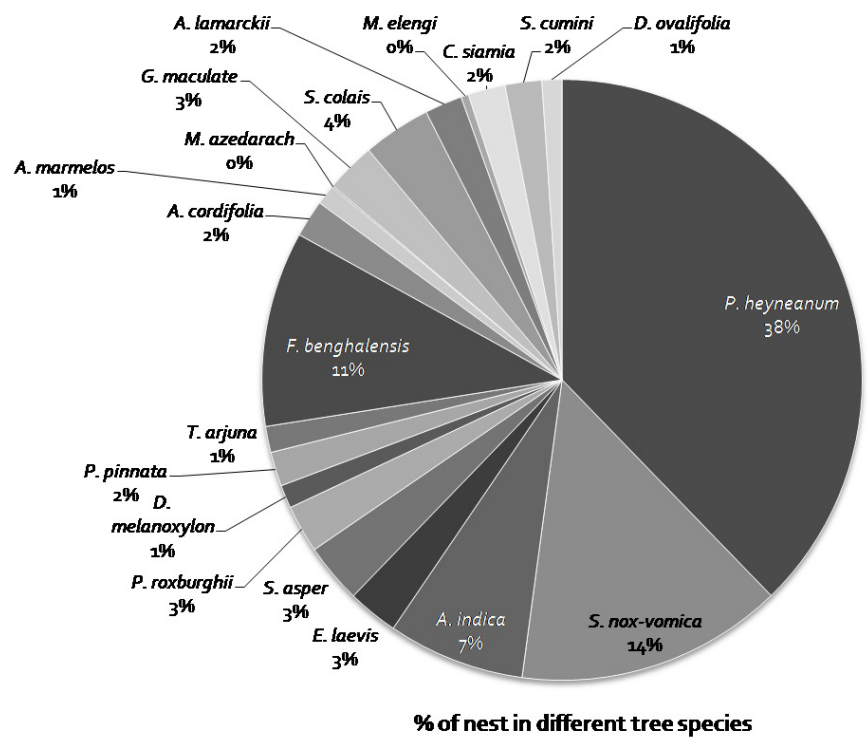

Figure 5 Percentage of nests in each tree species used for nesting of AOS

\section{Discussion}

The wetlands of NWS provide good food resources with minimal disturbance for the storks. Availability of water body in vicinity is instrumental in determining the vegetation pattern which in turn warrants adequate nest-site availability with sustainable food and nest-construction material for birds. ${ }^{14,15}$ We also believe that the availability of resources and conducive environment at NWS is the reason for nesting of AOS every year. Abundance of food resources in and around the heronry and the minimal disturbance due to the remoteness of the area are speculated to be the principal factors for this large congregation of breeding birds. ${ }^{8,16}$ Nesting in mixed colonies during monsoon has been reported, ${ }^{1}$ but in the present case monospecific nesting was observed. At Bhitarkanika National Park, Odisha, nesting of AOS was reported exclusively on E. agallocha trees and most of these trees are located in the centre of the heronry. ${ }^{16}$ Though AOS preferred $P$. heyneanum for nesting at the study site, it does not exclusively nest on this species. A total of 20 different nesting tree species were recorded in the present study. They also reported that AOS showed affinity to nest in the top canopy and their mean nest height was $14 \mathrm{ft}(4.26 \mathrm{~m}) .{ }^{16}$ We also observed similar affinity of AOS to nest on top canopy but the nesting height varies from $4.57 \mathrm{~m}-10.67 \mathrm{~m}$ (15-35 feet).

Nests are semi-circular to circular in shape and measured $30.21 \pm 0.12 \mathrm{~cm}$ in radius and with a depth of $6.9 \pm 0.02 \mathrm{~cm}$ approximately. ${ }^{17}$ The present study found similar shape of nests as described by Kanaujia et al. ${ }^{17}$ with $22-35 \mathrm{~cm}$ radius and $3-5 \mathrm{~cm}$ of depth. The nesting materials include twigs, leaves and grasses. Collection of nesting material continues from July till November. Both the sexes help to brood and feed the chicks. ${ }^{3}$ Movement of the chicks in the nest was reported at the age of 4-5 weeks onwards, whereas young birds observed flying to short distances from the nest at about 60 days. ${ }^{6}$ AOS mainly feeds on the molluscs of Pila sp. by inserting the tip of the mandible and dislodging the molluscan body from the shell apart from the regular notion that the gap in the bill is used like a nutcracker to crack the molluscan shell. ${ }^{3}$ The gap in the bill is absent in the juveniles. The juveniles feed on regurgitated feed on the nest., ${ }^{3,17}$ We observed chick in the nest around mid August. While in the nest the chicks were fed with regurgitated feed from parent storks. During 
first week of October the young storks feeding on snail were sighted; a sign of weaning. The area adjacent to the road was left up to $73 \mathrm{~m}$ to $89 \mathrm{~m}$ without nesting by the storks though similar vegetation was available in those areas. Dutta and $\mathrm{Pal}^{18}$ reported sound breeding of AOS in the human disturbed areas.

The dependence of storks on the particular nesting site makes the protection and scientific management crucial for their conservation. Although the present study described some major aspects of nesting habits of AOS, a number of questions like identification of tree species used for collection of nesting material, activity pattern of adult and young AOS, incubation period, incubation temperature, nest building behaviour, local migration route etc. remained unanswered and a matter of further study.

\section{Acknowledgments}

The authors are thankful to Prof. Sudarsan Maharana for his valuable suggestions in improvement of the manuscript.

\section{Conflicts of interest}

Author declares no conflicts of interest.

\section{References}

1. Rasmussen PC, Anderton JC. Birds of South Asia. The Ripley Guide. Second edn, National Museum of Natural History- Smithsonian Institution, Michigan State University and Lynx Edicions, Washington, DC: Michigan and Barcelona; 2012. p.1-378, 1-683.

2. Anam J, Ahmed M, Saikia MK, et al. Food and feeding behaviour of Openbill stork (Anastomus oscitans) in Assam. India J Glob Biosci. 2016;5(6):4188-4196.

3. Kahl MP. Food and feeding behaviour of the Openbill storks. Journal of Ornithology. 1971;112:21-35.

4. Grimmett R, Inskipp C, Inskipp T. Helm field guides Birds of the Indian subcontinent. Second edn. Delhi: Oxford University Press; 2011. p. $1-528$.

5. Ali S. The Book of Indian Birds. $13^{\text {th }}$ edn. BNHS: Oxford University Press; 2002. p. 1-326.
6. Pramanik AK, Santra KB, Manna CK. Nest-building behaviour of the Asian open billed stork Anastomus oscitans, in the Kulik bird sanctuary, Raiganj, India. Our Nature. 2010;7(1):39-47.

7. Kumar A, Kanaujia A. A flourishing breeding colony of Asian openbil stork (Anastomus oscitans) in Nawabganj bird sanctuary, Uttar Pradesh. International Journal of Extension Research. 2016;10:1-4.

8. Gopi GV, Pandav B. Observations on breeding biology of three stork species in Bhitarkanika mangroves, India. Indian Birds. 2007;3(2):4550

9. Panda P, Panda S. Floral Diversity of Nandankanan Wildlife Sanctuary. Odisha: Nandankanan Biological Park, Forest and Environment Department, Government of Odisha; 2012. p. 378.

10. Kamal S, Indresh GN, Mishra AK, Vertebrate faunal diversity of Kanjia Lake, Nandankanan. $e$-planet. 2009;7(2):29-33.

11. Panda S, Mishra S, Mishra AK, et al. Nandankanan Faunal Diversity. Odisha: Nandankanan Biological Park, Forest and Environment Department, Government of Odisha; 2010. p. 152.

12. Mohapatra RK, Panda S, Purohit KL. Wintering avian population of Nandankanan wildlife sanctuary, Odisha. Tigerpaper. 2013;1(2):31-34.

13. Mohapatra RK. Sighting of Indian grey hornbill and Rufous woodpecker at Nandankanan Wildlife Sanctuary, Odisha, India. Int J Avian \& Wildlife Biol. 2018; 3(4):307-308.

14. Raulings EJ, Morris K, Roache MC, et al. The Importance of Water regimes operating at small spatial scales for the diversity and structure of wetland vegetation. Freshwater Biol. 2010;55:701-715.

15. Garg A. Nest-plant correlation and predator preclusion in Asian openbill storks (Anastomus oscitans): a case study from Nawabgunj bird sanctuary, India. Indian Forester. 2016;142(2):179-186.

16. Gopi GV, Pandav B. Nest Space Partitioning among Colonial Nesting Waterbirds at Bhitarkanika Mangroves, India. World Journal of Zoology. 2011;6(1):61-72.

17. Kanaujia A, Kumar M, Kumar A, et al. Asian openbill: a colonial breeder. Green. 2014;8(3):1-9.

18. Datta T, Pal BC. The effect of human interference on the nesting of Openbill stork Anastomus oscitans at the Raiganj Wildlife Sanctuary, India. Biological Conservation. 1993;64:149-154. 